\title{
Improving Effects of FG-7080, a Serotonin Reuptake Inhibitor, on Scopolamine-Induced Performance Deficits of Memory Tasks in Rats
}

\author{
Naoyoshi Miura ${ }^{1}$, Naoki Nakata ${ }^{1}$, Yoshiaki Tanaka ${ }^{1}$, Yoshihiro Hiraga $^{1}$, Yugo Ikeda ${ }^{1}$, \\ Hisayuki Ohata ${ }^{2}$ and Tsuneo Iwasaki ${ }^{2}$ \\ 'Central Research Laboratories, Zeria Pharmaceutical Ca., Ltd., 2512-1 Oshikiri, Kohnan-machi, Ohsato-gun, Saitama 360-01, Japan \\ ${ }^{2}$ Institute of Psychology, University of Tsukuba, Tsukuba, Ibaraki 305, Japan \\ Received January 5, 1993 Accepted March 31, 1993
}

\begin{abstract}
A novel serotonin reuptake inhibitor, (-)trans 4-(4-fluorophenyl)-3-(4-methoxyphenoxymethyl)piperidine hydrochloride (FG-7080), was investigated for its effects on scopolamine-induced impairments in memory tasks of rats. In the radial-arm maze task, FG-7080 ( $3 \mathrm{mg} / \mathrm{kg}$, p.o.) improved the impaired performance. FG-7080 (1 mg/kg, p.o.) administered before the acquisition trial reduced the acquisition deficits in the passive avoidance task. Thus, the compound showed improving effects in the appetitive and aversive memory tasks. These findings suggest that FG-7080 may ameliorate the cognitive impairments caused by the cholinergic dysfunction.
\end{abstract}

Keywords: Serotonin reuptake inhibitor, Learning and memory, Scopolamine

(-)Trans 4-(4-fluorophenyl)-3-(4-methoxyphenoxymethyl)piperidine hydrochloride (FG-7080) is a novel non-tricyclic serotonin reuptake inhibitor (1). A number of recent reports indicate that selective serotonin reuptake inhibitors improve the performance of memory tasks in experimental animals (2), in addition to their anti-depressant effects. Furthermore, the learning and memory impairment induced by cholinergic dysfunction, which is thought to relate to human amnesic and/or dementia syndromes (3), is aggravated by lesioning of the serotonergic system (4). This report suggests that the brain serotonergic system interacts with the cholinergic system. In this study, we investigated effects of FG-7080 on impaired cognitive functions resulting from the treatment with a cholinergic antagonist, scopolamine hydrobromide (SCOP). To check if the drug effect was varied depending upon motivation, the effect of this compound was examined by using appetitively (radial-arm maze) and aversively (passive avoidance) motivated memory tasks.

In the radial-arm maze task, 3-month-old male Wistar rats were used. At the start of the experiment, the animals were placed into individual cages and their body weights were maintained at $85 \%$ of their free-feeding levels by restricted feeding throughout the experiment. The elevated 8-arm radial maze employed was described elsewhere (5). The training or drug-testing was conducted once a day according to the following procedure: Every arm of the maze was baited with $0.05 \mathrm{ml}$ of $30 \%$ sucrose solution in the reward hole at the end of each arm. The rat was placed on the central platform and allowed to obtain the reward. When it had consumed the reward from all 8 arms or $10 \mathrm{~min}$ had elapsed, it was removed from the apparatus. The learning criterion was at least 7 correct choices (entry into an arm not visited) in the first 8 choices in each of 5 consecutive trials. The drug testing trials were conducted at intervals of a few days using rats that had reached the learning criterion. On the days without drug treatments, ordinary training trials were given. FG-7080 (Novo Nordisk, Soeborg, Denmark) and idebenone (Avan $^{(}$, Takeda Chemical Industries, Osaka) were suspended in 5\% gum arabic and orally administered $30 \mathrm{~min}$ prior to the trial. SCOP $(0.25 \mathrm{mg} / \mathrm{kg}$, as hydrobromide salt; Nacalai Tasque, Kyoto) was dissolved in $0.9 \%$ saline and injected intraperitoneally $15 \mathrm{~min}$ prior to the trial.

The testings for FG-7080 at doses of 3, 10, 30, 100 $\mathrm{mg} / \mathrm{kg}$ and for idebenone at $10,30 \mathrm{mg} / \mathrm{kg}$ were carried out (high-dose testings). Fifteen animals were repeatedly tested under all drug conditions. Dosing orders were counter-balanced among the animals. Figure 1A shows the results of the high-dose testings of the radial-arm maze task. The number of correct choices in the first 8 choices was statistically analyzed by means of Wilcoxon's 

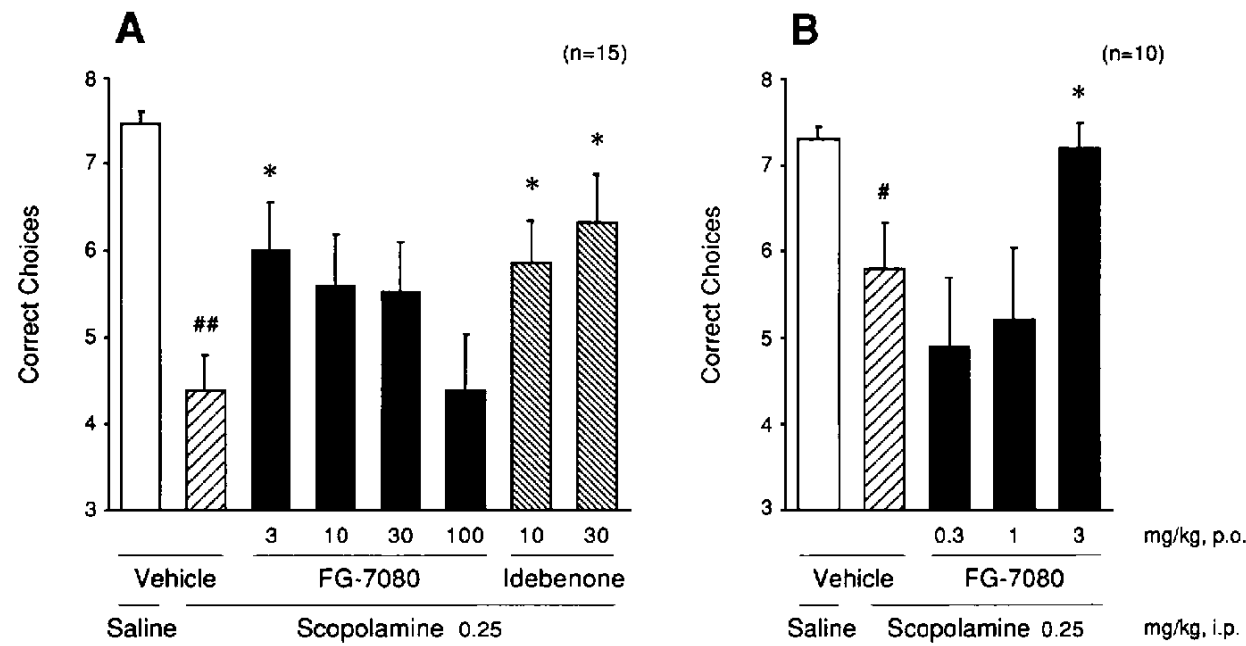

Fig. 1. Mean ( \pm S.E.) correct choices in the first eight choices in the radial-arm maze task. A) High-dose testings. B) Low-dose testings. ${ }^{*} \mathrm{P}<0.05,{ }^{4{ }^{*}} \mathrm{P}<0.01$ : significant difference from vehicle + saline. ${ }^{*} \mathrm{P}<0.05$ : as compared with vehicle + scopolamine treatment.

signed rank sum test. SCOP treatment significantly reduced the number of correct choices $(P<0.01)$. Administration of FG-7080 at $3 \mathrm{mg} / \mathrm{kg}$ resulted in a significant improvement of the performance $(P<0.05)$. The correct choices at doses of 10 and $30 \mathrm{mg} / \mathrm{kg}$ were increased, but they did not reach statistical significance. Idebenone improved the performance at doses of 10 and $30 \mathrm{mg} / \mathrm{kg}(\mathrm{P}<0.05)$.

Because a significant effect was observed only at the lowest dose, further testings with $3 \mathrm{mg} / \mathrm{kg}$ and lower doses of FG-7080 were conducted (low-dose testings). Eight rats that had been used in the high-dose testings, and two newly trained rats were employed in these testings. The same dosing-order was applied to all rats: vehicle + saline, $0.3 \mathrm{mg} / \mathrm{kg}+\mathrm{SCOP}, 1 \mathrm{mg} / \mathrm{kg}+\mathrm{SCOP}, 3$ $\mathrm{mg} / \mathrm{kg}+\mathrm{SCOP}$, vehicle $+\mathrm{SCOP}$. The results are presented in Fig. 1B. The correct choices under the $3 \mathrm{mg} / \mathrm{kg}$ of FG-7080 treatment condition were significantly greater than those with the vehicle treatment $(\mathrm{P}<0.05)$, as obtained in the high-dose testings. The performance under the vehicle + SCOP condition was better than that under the same condition in the high-dose testings. This increase of correct choices might have resulted from tolerance to SCOP and/or overtraining. Nevertheless, the beneficial effect against the SCOP-induced disturbance at the dose of $3 \mathrm{mg} / \mathrm{kg}$ of FG-7080 was reconfirmed in this experiment. The doses of 0.3 or $1 \mathrm{mg} / \mathrm{kg}$ did not affect the performance.

A step-through type apparatus (SFK-1, O'hara \& Co., Tokyo) was used for the passive avoidance task (6). Male Wistar rats, 7-week-old, were handled for $3 \mathrm{~min}$ on the day before an acquisition trial. Prior to the acquisition trial, they were allowed free exploration of the apparatus for $5 \mathrm{~min}$. A single acquisition trial was conducted $1 \mathrm{hr}$ after the free exploration. In that trial, a rat was first placed in a light compartment for $10 \mathrm{sec}$ and then a guillotine door was opened. When the rat entered a dark compartment, the guillotine door was lowered, and footshock ( $1 \mathrm{~mA}, 2 \mathrm{sec}$ ) was given through the grid floor. Twentyfour hours after the acquisition trial, a retention test was carried out using the same procedure as the training trial, except that no footshock was given, and the test was continued for $300 \mathrm{sec}$ after opening the guillotine door. The percentage of rats that did not enter the dark compartment throughout the retention test (percent retention) was

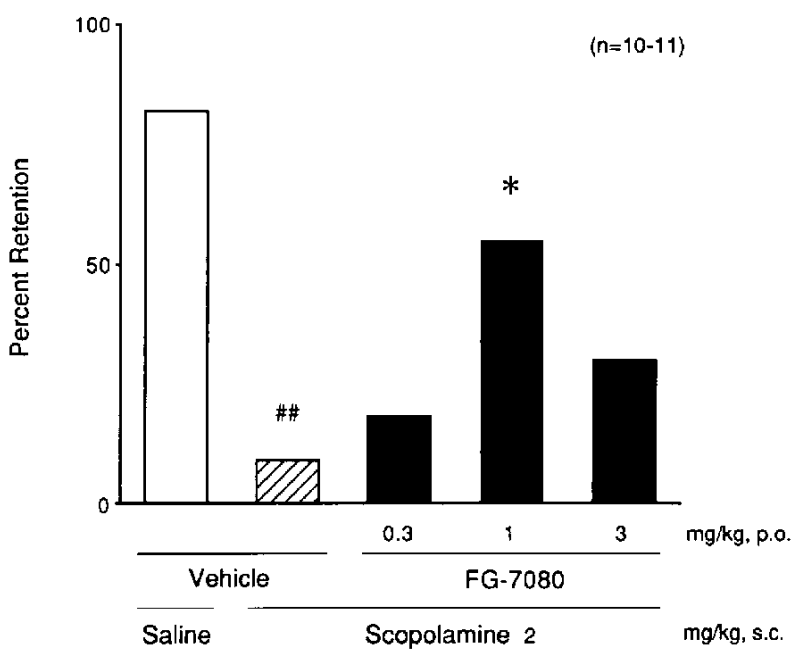

Fig. 2. Percent rats which did not enter the dark compartment up to $300 \mathrm{sec}$ (percent retention) in the passive avoidance task. ${ }^{* *} \mathrm{P}<0.01$; significant difference from vehicle + saline treated group. ${ }^{*} \mathrm{P}<0.05$ : as compared with vehicle + scopolamine treated group. 
taken as an index of the performance, which was examined by the $\chi^{2}$ test. FG-7080 $(0.3,1,3 \mathrm{mg} / \mathrm{kg})$ or its vehicle was orally dosed $55 \mathrm{~min}$ prior to the acquisition trial. SCOP $(2 \mathrm{mg} / \mathrm{kg})$ or saline was administered subcutaneously $30 \mathrm{~min}$ before the acquisition trial.

Results are shown in Fig. 2. Administration of SCOP reduced the percent retention $(\mathrm{P}<0.01)$. The performance in the animals treated with FG-7080 at $1 \mathrm{mg} / \mathrm{kg}$ was significantly superior to that in the vehicle-treated group $(\mathrm{P}<0.05)$.

FG-7080 improved the performance in the two tasks, the appetitively motivated radial-arm maze task and the aversively motivated passive avoidance task, at relatively low doses ( 3 and $1 \mathrm{mg} / \mathrm{kg}$, p.o., respectively). The compound causes no remarkable change in spontaneous motor activity at $3 \mathrm{mg} / \mathrm{kg}$, s.c. (Novo Nordisk, unpublished data) and footshock sensitivity in rats at $3 \mathrm{mg} / \mathrm{kg}$, p.o. (Zeria Pharmaceutical, unpublished data), indicating that the improvement of the memory task performance could not be a secondary consequence of the changes in specific motivational process, motor activity or footshock sensitivity. Instead, FG-7080 might affect the cognitive processes of the animal.

In this study, idebenone ameliorated the impaired radial-arm maze performance. It has been reported that idebenone alleviates the performance deficits caused by cholinergic dysfunction. Its mode of action to improve cholinergic function was suggested to be an indirect one, through its enhancing effects on cerebral metabolism and/or serotonin turnover $(7,8)$.

With regard to serotonin reuptake inhibitors, improvement of scopolamine-induced impairments of the memory task performance has been also shown under the treatments with citalopram (9) and fluoxetine (10). Altman et al. (11) reported that another serotonin reuptake inhibitor, alaproclate, potentiated the facilitatory effect of oxotremorine on the performance of the passive avoidance task. They suggested the involvement of serotonergiccholinergic interaction in this potentiation, in which the serotonergic system might be a modulator, and consequently, inhibition of serotonergic reuptake might enhance the activity of the cholinergic system (11). Therefore, it is postulated that FG-7080 ameliorates the disturbed state of the cholinergic system induced by SCOP through the serotonergic-cholinergic interaction.

FG-7080 strongly inhibits serotonin reuptake with an $I_{50}$ value of $20 \mathrm{nM}$ (1) and potentiates the behavioral effect of 5-hydroxytryptophan at $1 \mathrm{mg} / \mathrm{kg}$ (s.c.) in mice (Novo Nordisk, unpublished data). On the other hand, the compound shows relatively low affinity to muscarinic receptors. The $\mathrm{IC}_{50}$ value of $\left[{ }^{3} \mathrm{H}\right]$ quinuclidinyl benzilate binding was $6.6 \mu \mathrm{M}$ (Novo Nordisk, unpublished data). Tremorine-induced tremor in mice was inhibited at 10 $\mathrm{mg} / \mathrm{kg}$ or greater doses. Thus, anti-cholinergic effect of the compound was estimated to be about ten times weaker than that of imipramine. No inhibition was shown at 3 $\mathrm{mg} / \mathrm{kg}$ of FG-7080 (Zeria Pharmaceutical, unpublished data). Therefore, the muscarinic antagonistic activity of FG-7080 might not be exerted at the effective doses obtained in the present study. However, the reduction of the ameliorating effect at higher doses may partly result from direct muscarinic receptor antagonism. Further investigations are needed to determine the precise pharmacological mechanisms of FG-7080.

There are some reports indicating that selective serotonin reuptake inhibitors are effective for human mnemonic activities $(12-14)$. In patients with senile dementia of the Alzheimer type, citalopram alleviates attentional deficits (15). In the present study, FG-7080, the novel serotonin reuptake inhibitor, was shown to ameliorate the impaired performance of the memory tasks in rats. These data suggest that FG-7080 may be useful for treating human disorders with memory disturbances.

\section{Acknowledgment}

The generous gift of FG-7080 by Novo Nordisk A/S is gratefully acknowledged.

\section{REFERENCES}

1 Plenge, P., Mellerup, E.T., Honoré, T. and Le Fèvre Honoré, P.: The activity of 25 paroxetine/femoxetine structure variants in various reaction, assumed to be important for the effect of antidepressants. J. Pharm. Pharmacol. 39, 877-882 (1987)

2 McEntee, W.J. and Crook, T.H.: Serotonin, memory, and the aging brain. Psychopharmacology (Berlin) 103, 143-149 (1991)

3 Burtus, R.T., Dean, R.L., 3rd, Beer, B. and Lippa, A.S.: The cholinergic hypothesis of geriatric memory dysfunction. Science 217, 408-417 (1982)

4 Nilsson, O.G., Strecker, R.E., Daszuta, A. and Björklund, A.: Combined cholinergic and serotonergic denervation of the forebrain produces severe deficits in a spatial learning task in the rat. Brain Res. 453, 235-246 (1988)

5 Hiraga, Y. and Iwasaki, T.: Effects of cholinergic and monoaminergic antagonists and tranquilizers upon spatial memory in rats. Pharmacol. Biochem. Behav. 20, 205-207 (1984)

6 Hiraga, Y., Nakata, N., Jin, H., Ito, S., Sato, R., Yoshida, A., Mori, T., Ozeki, M. and Ikeda, Y.: Effects of the rice bran-derived phytosterol cycloartenol ferulic acid ester on the central nervous system. Arzneimittelforschung (in press)

7 Yamazaki, N., Nagaoka, A. and Nagawa, Y.: Effect of idebenone on scopolamine-induced impairment of short-term memory in rats. Japan. J. Psychopharmacol. 5, $321-328$ (1985) (Abs. in English)

8 Miyamoto, M., Nagaoka, A. and Nagawa, Y.: Effects of idebenone (CV-2619) on memory impairment in rats with basal forebrain lesions. J. Takeda Res. Lab. 44, 34-41 (1985) (Abs. in English)

9 Iwasaki, K., Matsumoto, Y. and Fujiwara, M.: Effect of 
citalopram on scopolamine-induced deficit of spatial cognition in rats. Abstracts for 17 th Congress of Collegium Internationale Neuro-Psychopharmacologicum, p. 334 (1990)

10 Flood, J.F. and Cherkin, A.: Scopolamine effects on memory retention in mice: a model of dementia? Behav. Neural Biol, 45, $169-184$ (1986)

11 Altman, H.J., Stone, W.S. and Ögren, S.O.: Evidence for a possible functional interaction between serotonergic and cholinergic mechanisms in memory retrieval. Behav. Neural Biol. 48, 49-62 (1987)

12 Weingartner, H., Rudorfer, M.V., Buchsbaum, M.S. and Linnoila, M.: Effects of serotonin on memory impairments produced by ethanol. Science 221, 472-474 (1983)

13 Martin, P.R., Adinoff, B., Eckardt, M.J., Stapleton, J.M.,
Bone, G.A.H., Rubinow, D.R., Lane, E.A. and Linnoila, M.: Effective pharmacotherapy of alcoholic amnesic disorder with fluvoxamine. Arch. Gen. Psychiatry 46, 617-621 (1989)

14 Nyth, A., Gottfries, C.G., Lyby, K., Smedgaard-Andersen, L., Gylding-Sabroe, J., Kristensen, M., Refsum, H-E., Öfsti, E., Eriksson, S. and Syversen, S.: A controlled multicenter clinical study of citalopram and placebo in elderly depressed patients with and without concomitant dementia. Acta Psychiatry Scand. 86, 138-145 (1992)

15 Nyth, A.L., Balldin, J., Elegen, K. and Gottfries, C.G.: Behandling med citalopram vid demens. normalisering av DST. Nord. Psykiatr. Tidsskr. 41, 423-430 (1987) (in Swedish, Abs. in English) 